\title{
Nutrition education and Mediterranean diet: exploring the teaching process of a school-based nutrition and media education project in Cretan primary schools
}

\author{
Irene Kafatos ${ }^{1}$, Antonis Peponaras ${ }^{2}$, Manolis Linardakis ${ }^{3}$ and Anthony Kafatos ${ }^{3, *}$ \\ ${ }^{1}$ Institute of Education, Sussex University, Brighton, UK: ${ }^{2}$ Hellenic Telecoms, Athens, Greece: ${ }^{3}$ Department of \\ Preventive Medicine, Faculty of Medicine, University of Crete, PO Box 1393, Iraklion, Crete, Greece
}

\begin{abstract}
Background: During the past few decades there has been a gradual abandoning of the traditional Mediterranean diet by the population of Crete and especially among the younger generations. Since this is related to the rapidly increasing morbidity and mortality rates from chronic diseases, the need for educating young people on the principles of good nutrition becomes increasingly important. It is also acknowledged that the epidemiological field needs to focus on studying the implementation process, since this will allow for a deeper understanding of the outcomes.

Objectives: The aims of the present study were to explore the process of implementing an innovation in Cretan primary schools and to identify best teaching practices and principles.

Design: In three state primary schools on the island of Crete, 107 children took part in a 30-h nutrition and media education programme. Classroom observations were used to define attitudes towards the programme and teaching methods. Besides baseline and post evaluation, the pupils were also interviewed about 11 months after the end of the programme.

Implementation: During observation of the teaching process, emerging issues were the teacher's motivation and interest in the course, his/her preparation before each class, teaching ability and communication skills, the respect and discipline he/she kept and the innovative teaching methods used. In some cases researcher intervention in the classroom could not be avoided.

Findings and conclusions: Overall, individual teacher willingness and teaching skills were mainly responsible for the quality of teaching, the variety of educational methods used in classrooms and pupils' interest in the course. Changes in pupils' knowledge and recall of the course were related to teacher enthusiasm but also to researcher intervention. Exploring the teaching and learning process allowed a deeper understanding of the data. It is concluded that attempts to introduce the principles of a Mediterranean diet to children through nutrition education require innovative, enthusiastic and highly motivated teachers.
\end{abstract}

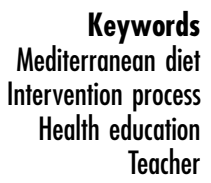

The goals of almost all nutrition education programmes internationally are set according to the traditional diet of Crete in the early $1960 \mathrm{~s}^{1}$. The renowned Seven Countries Study clearly demonstrated the advantageous position of the population of Crete regarding coronary heart disease mortality compared with other populations (Fig. 1) ${ }^{2}$. This situation holds true even when Cretans are compared with other Mediterranean populations. The protective effects of the Cretan diet were attributed to its high content of oleic and $n-3$ fatty acids and low content of linoleic and saturated fatty acids. In addition, high intakes of vitamins $\mathrm{C}$ and E, as well as of other non-nutrient antioxidants present in fruits and vegetables, were observed. A recent study carried out at the University of Crete School of Medicine compared a traditional diet, according to weekly weighed food records of the 1960s, with present-day foods by chemical analysis ${ }^{3}$. The study showed that the traditional dietary patterns and lifestyle of the Cretan population are currently being abandoned. While the older generation still maintains the traditional dietary pattern, this does not happen with youngsters who choose a more 'Westernised' diet. Table 1 presents a contemporary typical week's diet for the elderly, the middle-aged and children, and clearly portrays the different intakes of foods, and thus nutrients, between generations.

Children's diet, and the effect factors such as advertising might have on it, has set parents and authorities worrying and trying to find ways to solve the issue. Schools seem to be suitable places for any intervention to take place ${ }^{4-6}$. For example, in 1991, Lionis et al. ${ }^{4}$ performed medical 


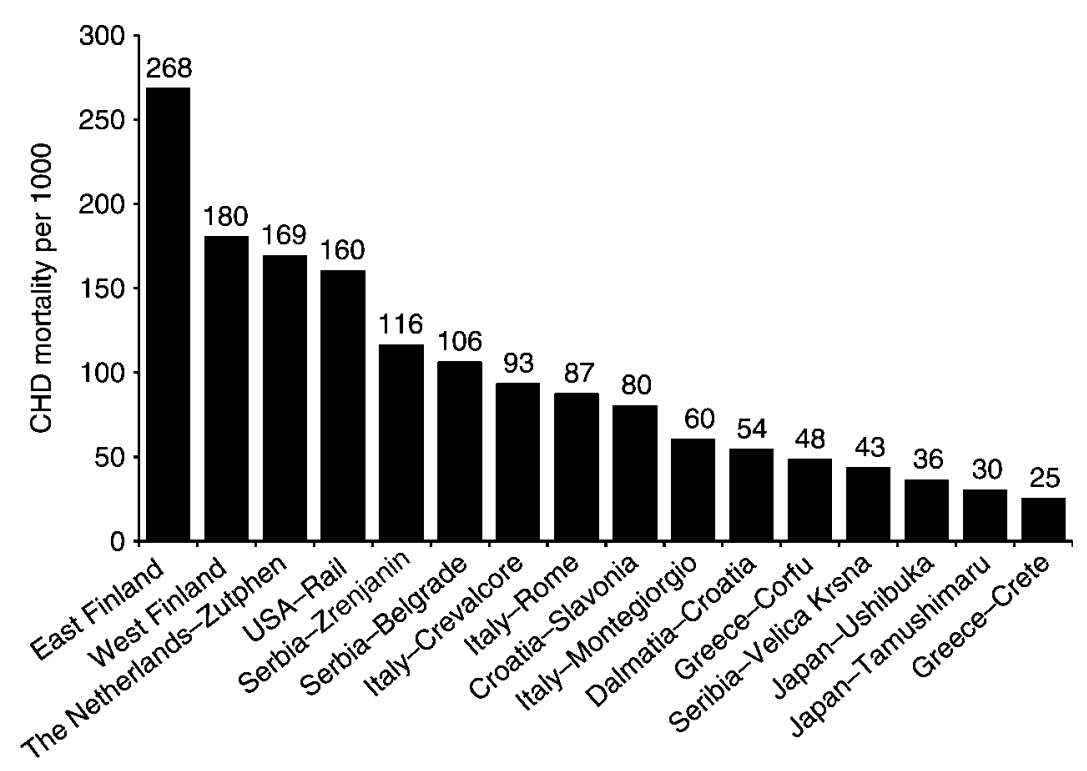

Fig. 1 Age-standardised 25-year mortality per 1000 from coronary heart disease (CHD) in 16 cohorts of the Seven Countries Study

examinations of 171 Cretan school students who had undergone a health education intervention programme and found that the programme was effective in decreasing some of the major risk factors for cardiovascular disease. The authors reported decreases in diastolic blood pressure and total serum cholesterol, a lower increase in body mass index compared with controls, and lower proportions of schoolchildren who started smoking ${ }^{4}$.

In most of the health promotion research cited above, strict design and statistical analysis are considered the bases necessary to achieve the outcome of objective results. Such studies very rarely present the process of implementing a programme. Nowadays, the importance of studying the implementation process and the need for a balance between qualitative and quantitative methods are acknowledged $^{7-13}$. Despite this, however, many studies continue to place most emphasis on quantitative approaches ${ }^{4,14-16}$. What this means is that the implementation process of a programme is either not examined or not considered important enough to be made public. Either way, the result is a plethora of studies where the implementation of an innovation resembles a 'black box ${ }^{, 7,17}$. According to this paradigm, the problem enters a black box where the process of implementation is not clear. In such cases, the emerging outcomes are the only source of information for the interpretation of what happened.

In the present study we chose to explore the intervention process of an education programme targeted on primary-school children. The aim of the programme was to help children develop an understanding of the basic principles of nutrition and of the function and aims of food advertisements. The belief was that making the grounds of advertising open and more accessible to children, while they were also given the basic knowledge and skills to improve their nutrition habits, would allow youngsters to make better food choices not only for the duration of the course but also in the long term.

The focus of the study was not on quantitative data and statistical analysis but instead on the implementation of the educational programme. This paper shows how the

Table 1 Mean daily food consumption in three different age groups from Crete*

\begin{tabular}{|c|c|c|c|}
\hline Food group & $\begin{array}{c}\text { Men aged } 77-79 \\
\text { years from a } \\
\text { rural area, } \\
1997-98 \\
(n=160) \dagger\end{array}$ & $\begin{array}{c}\text { Men aged } 40-60 \\
\text { years from a } \\
\text { rural area, } 1997 \\
(n=98) \ddagger\end{array}$ & $\begin{array}{l}\text { Children aged } 12 \\
\text { years, } 1998 \\
(n=90)\end{array}$ \\
\hline Milk \& dairy products & 176 & 123 & 234 \\
\hline Meat \& meat products & 49 & 86 & 106 \\
\hline Fish \& fish products & 27 & 38 & 29 \\
\hline Cereals (including bread) & 222 & 337 & 308 \\
\hline Legumes & 63 & 54 & 33 \\
\hline Vegetables & 295 & 435 & 186 \\
\hline Fruit & 337 & 351 & 123 \\
\hline Sugar, confectionery, chocolate & 50 & 15 & 43 \\
\hline
\end{tabular}

* University of Crete, unpublished data.

† Seven Countries Study, Cretan cohort.

$\ddagger$ Younger cohort of men examined in 1997 with the Seven Countries Study cohort. 
implementation differed between particular classes, a fact that affected the teaching-learning process. Classroom observation enabled an understanding of the complexity of the situation, and served as a tool for exploring best teaching practices and the problems encountered.

\section{Methods}

Participants were five Year 5 classes (average age 10 years) of three state primary schools in Iraklion, Crete (total number of children, 107). The pupils were taught the course, which lasted for about $30 \mathrm{~h}$, over a period of 5 months (November 1997-March 1998). About 11 months after the end of the innovation (January 1999) the pupils were interviewed again by the researcher; these are the data presented herein.

The four participant teachers were all volunteers and had expressed an interest in the programme. Dimos, Katia and Michalis were experienced primary-school teachers. Andreas was his school's gym instructor, and had only a few years of teaching practice. His volunteering meant his pupils had to stop having their gym lessons - a factor quite detrimental for the success of the course. Pupils' socioeconomic background was also important. Katia taught in a school located in an upper middle class, high-status area. Michalis and Dimos both taught in a working class, deprived area; Andreas's school was also in a working class area, but of intermediate status.

The educational programme included media, nutrition and consumer education issues as its basic focus. The programme helped children develop an understanding of how advertisements are made by making their own adverts, how the advertising business works, as well as the basic principles of good nutrition and how foods are presented through adverts and reading food labels. Its novelty was found in approaching advertisements in a way that was often enjoyable and fun. Pupils were invited to participate and discuss their feelings, experiences and thoughts, and to criticise television food advertisements.

The researcher was present every time teaching of the course took place. Classroom observation permitted the researcher to obtain qualitative data on how the children and the teachers responded to the programme. Data collection covered children's knowledge on nutrition and their recall of the content and methods of the course.

\section{Implementation}

In this research, classroom observation was the means to evaluate whether teaching practices enabled the implementation of the innovation to take place. It was during classroom observation that the researcher realised the differences of implementation were considerable. It was stunning to see how the same course was taught by teachers and received by pupils in different classrooms.
The quality of implementation differed so markedly that it became necessary to take account of this dimension. Moreover, this realisation had a direct and immediate effect on the researcher and led to an important change to the research model: participatory observation.

A set of criteria (Table 2) found in the literature ${ }^{18,19}$ was used for evaluating teaching practice. These were applied throughout the evaluation of the whole teaching period and not based on just a single test or data collection at the end of the intervention.

\section{Effective teaching qualities}

According to Ayers and Gray $^{18}$, effective teaching qualities include vigilance and flow (avoid abrupt transitions). We would also add, flexibility of teacher conceptions and thinking. Dimos proved to be quite flexible when he explained to his class that recipe, quantity and frequency of consumption often determine how 'healthy' foods may be. On the other hand, Katia appeared to be more rigid in her judgement of foods, which caused complaints in her classroom. Such a dogmatic position, however, which allowed for no alternatives and might contradict pupils' beliefs, could in some cases discredit the course and threaten its effectiveness.

On the other hand, apart from flexibility, effective teaching was portrayed in successful whole class discussion. For instance, Andreas had trouble directing the discussion and often his class had to guess what he was driving at. His very general question 'What is the first thing you do when you return to home after school?' did not lead to Andreas's expected answer of 'I open the refrigerator'. Instead he got answers like 'I wash my hands and have lunch', 'I start studying', etc. In the end he had to give the answer himself. Thus Andreas often strayed from the main topic, and this usually resulted in his pupils not seeing the relevance of his points in relation to what was supposed to be taught. It is likely that Andreas's physical education (PE) training and role in the school had not prepared him for the tasks he needed to perform within the classroom, while the pleasure the pupils felt in association with the PE lesson did not allow them to take Andreas seriously in class. Moreover, he did not have the ability to keep the pupils' interest while he talked and his class would soon get bored and start chatting. On more than one occasion, the pupils tried to pull the researcher into teaching.

Table 2 Criteria for evaluating teacher implementation ${ }^{18,19}$

\begin{tabular}{lllll}
\hline Criterion & Dimos & Michalis & Katia & Andreas \\
\hline $\begin{array}{c}\text { Effective teaching qualities } \\
\text { (discipline, preparation) }\end{array}$ & yes & no & yes & no \\
$\begin{array}{c}\text { Pupils engaged in the } \\
\text { learning process }\end{array}$ & more & less & more & less \\
$\begin{array}{c}\text { Teacher commitment to the } \\
\text { innovation }\end{array}$ & yes & no & yes & no \\
\hline
\end{tabular}


Often Andreas did not really pay much attention to what the children said. He missed answers that would have been worth exploring and could have provided the basis for an interesting discussion.

Concerning preparation, Michalis often came unprepared for the lessons - frequently asking the researcher on the day which lesson he was supposed to do (!) These inadequacies affected the implementation in the sense that the teachers lacked enthusiasm and the ability to connect the theory learned to pupils' responses.

Classroom discipline was an equally important issue. With little teaching experience, Andreas was not always able to maintain order in his classes and the high noise level and discipline problems he faced almost equated to non-implementation of the programme.

\section{Keep pupils engaged in learning}

The importance of keeping pupils engaged in the learning process was manifested on more than one occasion. In the first example that follows, Katia's class worked with great interest in counting and commenting on the frequency of food advertisements. Pupils were supposed to watch television at home and write down all advertisements they saw on particular kinds of products (namely fruits/vegetables, salty food and soft drinks). Their results were to be discussed in the classroom at the following lesson.

Katia asks the children to say what they think of these results and a pupil says that the foods advertised more frequently are salty foods and soft drinks and rarely fruit and vegetables.

Another pupil says that people like salty foods and fizzy drinks better and that is why these are advertised most. Katia says here that we should be careful with adverts and use our mind to judge what they tell us. She and the pupils also notice that in TV food adverts there is a reverse food pyramid: bottom at top and top at bottom as if we should eat mostly the 'unhealthy' foods. (Researcher diary, lesson 12 in Katia's class, 11/03/1998)

The activity linked theory with practice as the pupils observed whether television adverts follow the advice on good nutrition.

\section{Teacher commitment to the course}

Individual teachers' differing enthusiasm and commitment to the course resulted in different time and significance given to the same activity. The following extracts from two different classes emphasise this difference.

In the lesson on fruit juice and soft drinks, a cartoon story (Garfield) was used in the classroom as a chance for discussion on understanding the value of food labels. In Dimos's class:

P: It's a cat and finds $a$ box and puts the food in his plate. He looks what is inside the box and although be didn't know what it is inside be ate it.

P2: He didn't know the ingredients.

T: So, what happened at the end?
P1: He didn't know what was inside the box.

\section{T: Didn't he?}

P2: He didn't know the ingredients.

T: So, what happens in the first picture? Where do you think the cat's food comes from?

P3: The box.

T: [...JOf course in the place of Garfield it could be a person, it could be you. Imagine you are eating and right there, next to you, there is the box where your food is coming from. So, your first reaction is to wonder. What happens in the next picture?

$P$ : He looked at the ingredients and wasn't satisfied with them.

T: Right. How do you know he wasn't satisfied with what be saw?

P: His cheeks are full with food, he hasn't swallowed yet.

T: Ok, his expression shows Garfield doesn't like...

P: The food.

T: He may like the food, the taste but not what he saw it is inside. How about the third picture?

P1: He eats the food.

P2: Although be doesn't know the ingredients he eats it.

P3: What he was interested in was the taste.

T: Good. What is this 'bmmm' sound Garfield makes?

P1: He likes the food.

P2: He wonders what's in the box.

T: Right, he wonders. I eat something and I want to see what it is. What does Garfield say in the next picture?

$P$ (reads): 'Ingredients: You're better off not knowing.'

T: Why do you think Garfield says so?

P1: Because be can't read.

T: Can't he?

P2: Because the food is not bealthy.

T: Yes, and the cat makes a comment in the third picture.

$P$ (reads): 'What you don't know can't hurt you right?'

T: Right, the cat thinks, 'if I read what's inside maybe in the end I won't have any appetite left'. All foods list on their wrappings the ingredients used to make them. Now, if you were in the cat's place, would you agree with what be did?

P1: Yes, with number 1 and 2.

T: Yes.

P: But in the third picture be doesn't mind what he eats. I don't agree with that.

T: Yes. It's very important to know what you eat. Let me give you an example.

(Transcript, Dimos's class, 22/12/1997; P = pupil, $\mathrm{T}=$ teacher, $\mathrm{P} 2=$ pupil 2 , etc.)

With Michalis, an experienced but unenthusiastic teacher, things were quite different:

T: As you can see there is a cat, Garfield, and he is about to eat cat food. And then he is thinking: It doesn't matter if I don't know what's inside. Is this correct?

P1: No.

P2: Yes 
T (turns to the pupil who said yes): Is it correct to eat something without knowing what's inside?

P2: No.

T: Look at the third picture. Would you do what he does?

P: No.

T: I don't think anyone eats without knowing what's inside what he eats. What you should do when you buy a product is not only to look at the expiration date but also at its ingredients. Also, is this product made in Greece or some place else?

P: How do we get to know this, sir?

T: You should look on its package.

P: What if it doesn't write it?

T: This can't be. All products must state name of manufacturer. If it doesn't write where it comes from, you shouldn't buy it.

(Transcript, Michalis's class, 13/01/1998)

The same textbook story started a long discussion in the first case but a very short dialogue in the second class. Note the fact that Dimos's questions had to be thought about before they were answered in full phrase answers while Michalis's pupils answered either 'yes' or 'no'. In another class the teacher simply asked the questions written below the text. Also Dimos's pupils progressed at their own pace and thinking to the conclusion of the story, while Michalis hurriedly proceeded to the end. As noted in researcher field notes:

Michalis tends to talk most of the time and give the main points to the pupils bimself. The pupils do talk but either between them (chattering) or giving examples to what Michalis says.

Through transcriptions and field notes it became clear how the four participating teachers each had their own pedagogy, which in consequence led to a different position adopted by the researcher in each class. Katia and Dimos appeared to share the same enthusiasm, commitment and high ability to teach the innovation. Andreas and Michalis were both less able and, in the latter's case, less willing to teach. Such variations, however, were found to have a direct impact on pupil's learning and consequently on their dietary improvement.

\section{Findings and conclusions}

The aim of this study was to present the implementation process of an educational intervention, and to identify best teaching practices. To point this out, we now focus on particular examples and data, which show teachers being evaluated both by pupils and the researcher.

Pupil evaluation of teachers lies in the children's acquired nutrition knowledge and recall of the course after a period of 11 months from the end of the implementation. Pupil reliability was tested from their answers on common-sense judgement questions, e.g. 'Are fruit/vegetables healthy for us or not?' Reliability for all classes was found to range between 83.7 and $91.2 \%$. Figure 2 shows children's correct answers on a particular nutrition education question. Pupils were asked to evaluate a set of foods with respect to whether they considered them healthy or not. Results are presented per class and the teachers are put in an evaluation order according to their performance indicator. Katia had high scores and unexpectedly Michalis scored higher than Dimos. Similar results are found when we look at Fig. 3, pupils' recall of the course. The children were asked to recall the number of items they remembered on the nutrition and advertising part of the course. It is characteristic that, besides content, the pupils mentioned participatory activities such as making their own advert, and a food pyramid which were highly recalled. Again Katia is by far the first, with the other teachers following.

The results may not be so surprising considering the classroom observation data. Teachers like Katia and Dimos showed a high degree of interest and enthusiasm coupled with good teaching abilities and skills. Katia's high scores can also partly be interpreted within the context of her pupils' middle class status, i.e. articulate children who knew how to express their feelings. Dimos's children also exhibited much improvement despite their

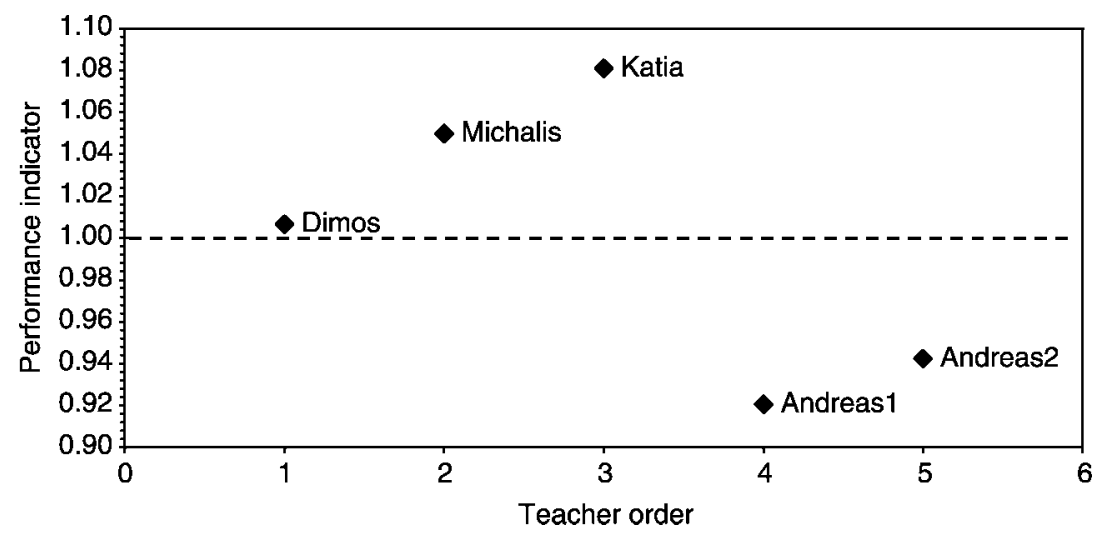

Fig. 2 Teacher performance indicator according to pupils' knowledge 


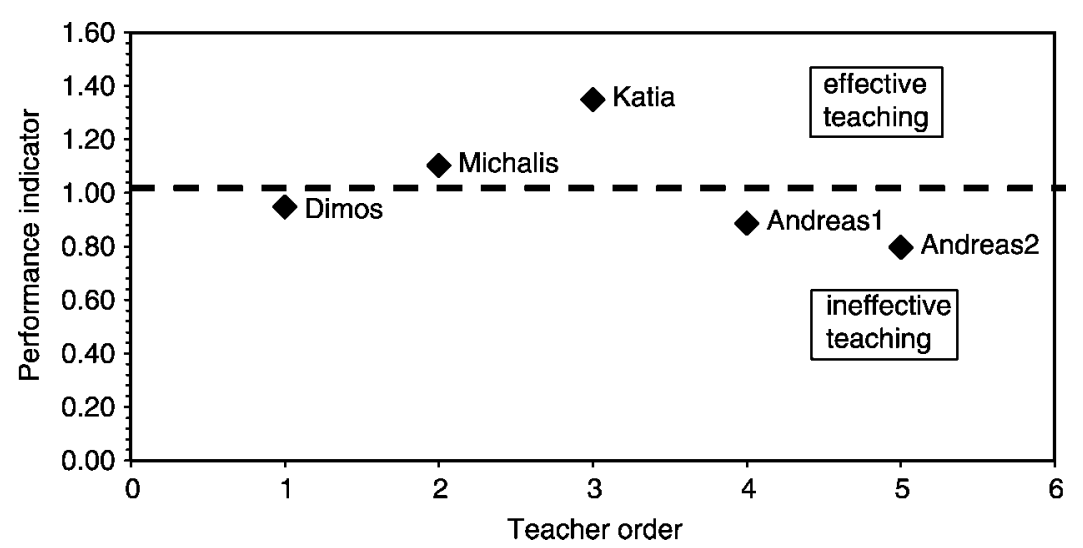

Fig. 3 Teacher performance indicator according to pupils' recall of course

deprived-area, working class background. Therefore, it seems safe to conclude that teacher abilities and enthusiasm alone are responsible for pupils' improved learning.

Teachers like Michalis and Andreas showed indifference and/or lack of teaching abilities. Both of these teachers had grave discipline problems, which seriously hindered the implementation. Due to their unsuccessful teaching, the initial design for non-participatory observation was abandoned (Fig. 4). Such researcher intervention, however, offered an unexpected 'balance' in the differences between the classes. It seemed the lower was the teacher's ability to implement the innovation, the higher was the researcher's intervention trying to 'save what could be saved'. Both these classes received a substantial amount of researcher intervention. In other words, the lack of implementation by the teacher was countered by the researcher, who consequently balanced the results.

Researcher evaluation of teachers, which was a result of classroom observation, is presented along with the children's evaluation in Fig. 5. Katia remains the first in both the researcher's and the children's evaluation. Dimos, although highly evaluated by the researcher, was not so well evaluated by his pupils. Michalis's lack of enthusiasm and preparation was balanced by high researcher intervention and willingness on the part of the pupils to participate in the course. These children were more enthusiastic than any other class and this, besides researcher intervention, is another likely explanation of his class's high evaluative grade. In Andreas's case the unpopular cancellation of the PE class in favour of the innovation resulted in the pupils having a negative reaction to the course, which was retained throughout the implementation.

It is now clear that the actual implementation differed very much among the classes. The observation of the implementation process allowed in-depth exploration of the impact of the innovation. Although all four teachers were volunteers, had expressed interest in the programme and had all been equally informed, provided with the course material and help, only two were able to 'successfully' implement the innovation. In the other two classes, the researcher felt morally obliged to participate and ensure that the pupils at least did not waste their time. In other words, in these classes the researcher substituted for the teacher's inadequacy, which had the effect of balancing the results between the categories of strong and weak implementation.

Thus the usual control-experimental analysis moved on a step further: to analyses within the experimental group. Consider, for instance, a 'failure' (no differences between the control and experimental group) of the implementation. One could only speculate as to the reasons. Exploration of the process enabled the researcher

घTotal teaching time (h) $\square$ Teaching time (h) שResearcher intervention time (h)

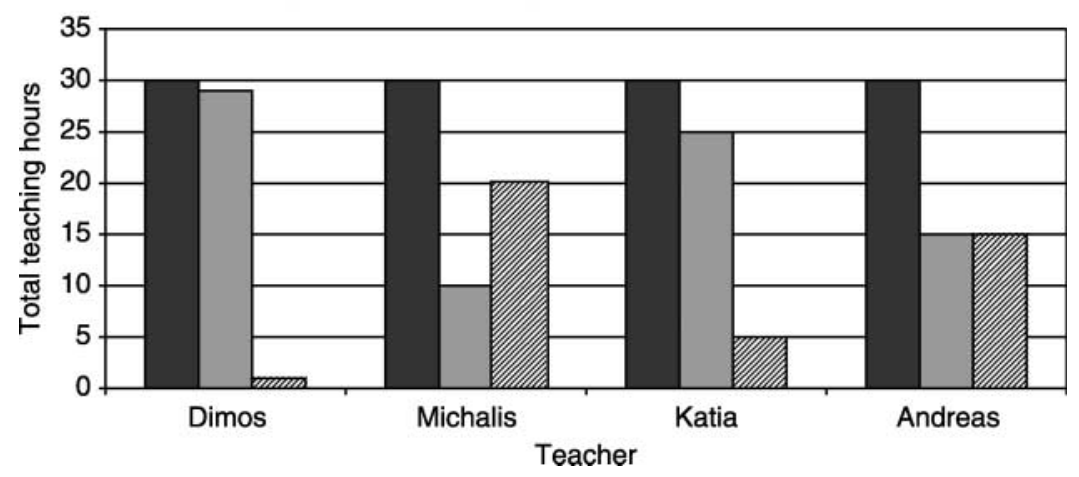

Fig. 4 Researcher's intervention in class 
घResearcher's evaluation $\square$ Children's evaluation ₫ Mean evaluation

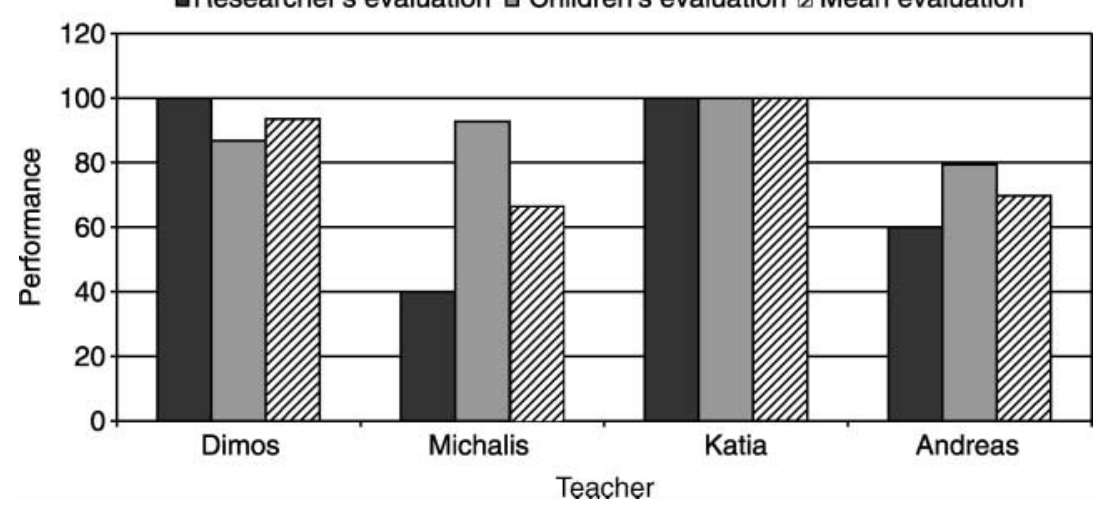

Fig. 5 Researcher's and children's evaluation of teacher performance

to say whether there had been a problem in the design of the implementation or whether the problem lay within a particular class. The method is, of course, demanding on one's time and negotiation skills but the data are rewarding and understanding is deeper and more complex.

\section{References}

1 Keys A, Blackburn HW, Van Buchem FSP, Buzina R, Djordjevic BD, Dontas AS, et al. Epidemiological studies related to coronary heart disease: characteristics of men aged 40-59 in seven countries. Acta Medica Scandinavica. Supplementum 1966; 460: 1-392.

2 Menotti A, Kromhout D, Blackburn H, Fidanza F, Buzina R, Nissinen A for the Seven Countries Study Research Group. Food intake patterns and 25-year mortality from coronary heart disease: cross-cultural correlations in the Seven Countries Study. European Journal of Epidemiology 1999; 15: $507-15$.

3 Kafatos A, Verhagen H, Moschandreas J, Apostolaki J, Van Westerop JJ. Mediterranean diet of Crete: foods and nutrient content. Journal of the American Dietetic Association 2000; 100: $1487-93$.

4 Lionis C, Kafatos A, Vlachonikolis J, Vakaki M, Tzortzi M, Petraki A. The effects of a health education intervention program among Cretan adolescents. Preventive Medicine 1991; 20: 685-99.

5 Green L, Iverson D. School health education. Annual Review of Public Health 1982; 3: 321-38.

6 Kelleher C. Health promotion: shades of Lewis Carroll. Journal of Epidemiology and Community Health 1995; 49: $1-4$.

7 Susser M. Does risk factor epidemiology put epidemiology at risk? Peering into the future. Journal of Epidemiology and Community Health 1998; 52: 608-11.

8 McPherson K. Wider 'causal thinking in the health sciences' [Commentary]. Journal of Epidemiology and Community Health 1998; 52: 612-8.
9 Poole C, Rothman K. Our conscientious objection to the epidemiology wars [Commentary]. Journal of Epidemiology and Community Health 1998; 52: 612-8.

10 Mackenbach J. Multilevel ecoepidemiology and parsimony [Commentary]. Journal of Epidemiology and Community Health 1998; 52: 612-8.

11 Vineis P. Epidemiology between social and natural sciences [Commentary]. Journal of Epidemiology and Community Health 1998; 52: 612-8.

12 Morabia A. Epidemiology and bacteriology in 1990: who is the handmaid of whom? [Commentary]. Journal of Epidemiology and Community Health 1998; 52: 612-8.

13 Scott-Samuel A. Health impact assessment - theory into practice. Journal of Epidemiology and Community Health 1998; 52: 704-5.

14 Bush P, Zuckerman A, Theiss P, Taggart V, Horrowitz C, Sheridan $\mathrm{M}$, et al. Cardiovascular risk factor prevention in black schoolchildren: two-year results of the 'Know your Body' program. American Journal of Epidemiology 1989; 129(3): 466-82.

15 Parcel G, Simons-Morton B, O'Hara N, Baranowski T, Kolbe L, Bee D. School promotion of healthful diet and exercise behaviour: an integration of organisational change and social learning theory interventions. Journal of School Health 1987; 57(4): 150-6.

16 O'Loughlin J, Paradis G, Kishchuk N, Gray-Donald K, Renaud L, Fines P, et al. Coeur en sante St-Henri - a heart health promotion programme in Montreal, Canada: design and methods for evaluation. Journal of Epidemiology and Community Health 1995; 49: 495-502.

17 Lacey C, Jacklin A. The White Paper on International Development, Education Development Projects and Bureaucratic Cultures. Paper for the Inaugural Conference of the British Association of International and Comparative Education, University of Reading, September 1998.

18 Ayers H, Gray F. Classroom Management. London: David Fulton Publishers, 1998.

19 Hurst P. Implementing Innovatory Projects: A Critical Review of the Literature. London: The British Council, 1978. 